
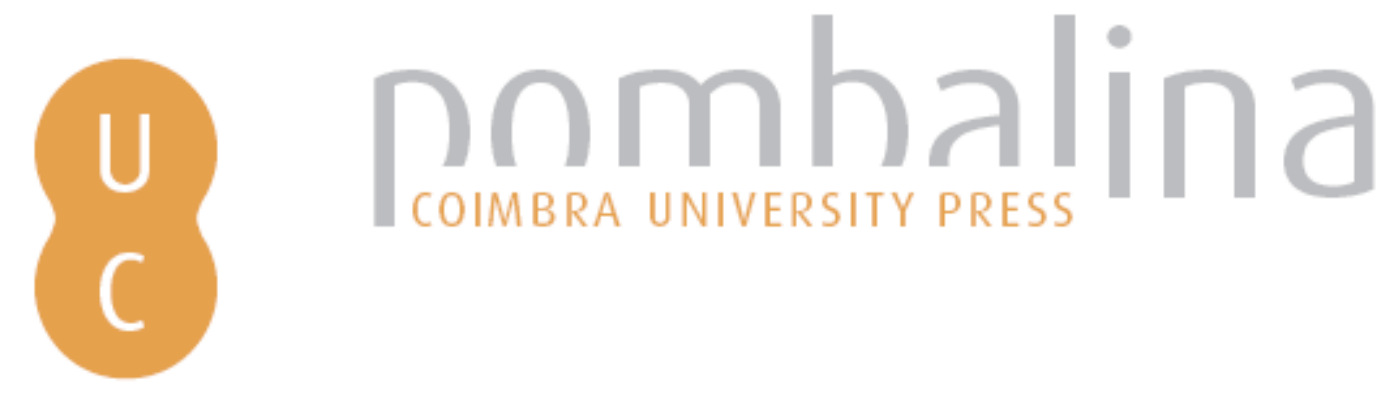

\title{
Relações RússiaTurquia: da rivalidade à parceria estratégica
}

\author{
Autor(es): $\quad$ Barrinha, André
}

Publicado por: Imprensa da Universidade de Coimbra

URL

persistente: URI:http://hdl.handle.net/10316.2/31919

DOI: $\quad$ DOI:http://dx.doi.org/10.14195/978-989-26-0712-2_9

Accessed : $\quad$ 19-May-2017 18:12:33

A navegação consulta e descarregamento dos títulos inseridos nas Bibliotecas Digitais UC Digitalis, UC Pombalina e UC Impactum, pressupõem a aceitação plena e sem reservas dos Termos e Condições de Uso destas Bibliotecas Digitais, disponíveis em https://digitalis.uc.pt/pt-pt/termos.

Conforme exposto nos referidos Termos e Condições de Uso, o descarregamento de títulos de acesso restrito requer uma licença válida de autorização devendo o utilizador aceder ao(s) documento(s) a partir de um endereço de IP da instituição detentora da supramencionada licença.

Ao utilizador é apenas permitido o descarregamento para uso pessoal, pelo que o emprego do(s) título(s) descarregado(s) para outro fim, designadamente comercial, carece de autorização do respetivo autor ou editor da obra.

Na medida em que todas as obras da UC Digitalis se encontram protegidas pelo Código do Direito de Autor e Direitos Conexos e demais legislação aplicável, toda a cópia, parcial ou total, deste documento, nos casos em que é legalmente admitida, deverá conter ou fazer-se acompanhar por este aviso.

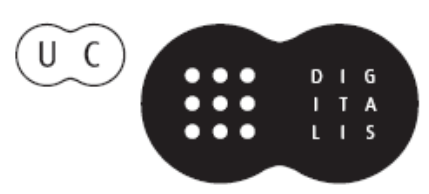


IMPRENSA DA

UNIVERSIDADE

DE COIMBRA

COIMBRA

UNIVERSITY

PRESS

\section{A POLÍTICA EXTERNA \\ RUSSA NO ESPAÇO \\ EURO-ATLÂNTICO}

$\therefore:$

\section{Dinâmicas de cooperaçấo e}

competiçẫo num espaço alargado

PÁTRICIA DAEHNHARDT

MARIA RAQUEL FREIRE

Coordenadoras 
(Página deixada propositadamente em branco) 


\section{CAPÍTULO 9}

\section{RELAÇÕ ES RÚSSIA-TURQUIA：DA RIVALIDADE À PARCERIA ESTRATÉGICA}

André Barrinha

Das inúmeras guerras entre o Império Otomano e o Império Russo, aos recentes acordos energéticos entre Ancara e Moscovo, o relacionamento entre a Turquia e a Rússia foi sempre marcado por uma grande ambiguidade. Essa é uma ambiguidade derivada da inevitabilidade da proximidade geográfica, da sobreposição parcial de interesses geoestratégicos, do reconhecimento mútuo das mais valias que um relacionamento próximo oferece e, sobretudo, de uma forma de entender política externa baseada em pressupostos tendencialmente realistas. Pressupostos associados à forma de fazer política externa destes dois países, mas também ao facto de estarmos perante duas potências em ascensão na cena internacional.

A Rússia e a Turquia fazem parte de um conjunto de potências emergentes no sistema internacional, cuja ascensão tem sido alicerçada no crescimento económico e na atomização dos relacionamentos geopolíticos, sendo possível afirmar que atravessam o período mais pacífico e cooperativo da sua história (Ediger e Bagdadi, 2010, p. 223).

Pela sua crescente importância internacional e por serem os dois maiores vizinhos da União Europeia (UE) e logo, atores fulcrais no sucesso das políticas europeias relativamente à sua vizinhança tanto a sul como a leste, é fundamental perceber o estado do relacionamento entre estes dois países, bem como as eventuais tendências de evolução desse mesmo relacionamento. Como tal, este capítulo começará por fazer um breve 
resumo da evolução histórica do relacionamento, dando um claro enfoque ao período pós-Guerra Fria. A isso segue-se uma análise da relação entre estes dois países na atualidade, com destaque para as principais áreas de interação entre ambos. Na terceira e última parte, será feita uma análise crítica do mesmo onde se tentará inferir sobre os padrões de comportamento que marcam as relações entre a Rússia e a Turquia.

\section{Turquia-Rússia: da rivalidade passiva à parceria estratégica}

Atualmente separados pelas repúblicas do Cáucaso do Sul, a Turquia e a Rússia foram até ao fim da Guerra Fria países com fronteiras comuns, ambições paralelas e alianças antagónicas. O relacionamento entre estes dois atores nunca foi particularmente positivo (Warhola e Mitchell, 2006, p. 129), correspondendo a um padrão de comportamento que recua aos Impérios Otomano e Russo. Apesar de o relacionamento entre os dois Impérios recuar a 1492, ano em que o Czar Ivan III enviou uma delegação diplomática a Istambul (MFA, 2008), foi a partir de finais do século XVII que Constantinopla

e São Petesburgo "intensificaram" o seu relacionamento, neste caso, pelas piores razões. Entre 1676 e 1917, a Turquia e a Rússia foram adversários em doze guerras, o que dá uma média de uma guerra a cada vinte anos durante este período (Ediger e Bagdadi, 2010, p. 223). De entre estas, a guerra de 1768-74 teria um significado especial, pois a pesada derrota das forças otomanas significou o fim da sua hegemonia no Mar Negro e, até certo ponto, o início do declínio do Império da Sublime Porta (idem).

No entanto, boa parte do projeto hegemónico de cada uma destas potências passava pela conquista de territórios distintos: a Rússia preocupava-se com a Europa de leste, a Ásia Central e o Cáucaso. A Turquia, sobretudo com o Médio Oriente e os Balcãs, mas também com o Cáucaso, de resto o principal ponto de fricção entre as duas potências.

Se no caso russo, a revolução comunista levou à retirada do país da Primeira Guerra Mundial, no caso turco a opção pela Tríplice Entente, juntamente com a desintegração interna do Império Otomano, levaram a que a Turquia fosse reduzida a pouco mais que o planalto da Anatólia. 
Nesse sentido, toda a segunda metade do século XX, até ao fim da Guerra Fria foi ditada pelo desequilíbrio entre uma URSS Império e uma Turquia pós-Imperial sobretudo preocupada com a consolidação do seu projeto republicano, marcada pelo princípio de Mustafa Kemal 'Ataturk', "paz em casa, paz no mundo" (Kazan, 2005, p. 591).

Curiosamente, o projeto de Mustafa Kemal teria provavelmente falhado sem o apoio de Lenine, que, ao contribuir com o envio de armas e mantimentos, permitiu às forças rebeldes comandadas por Ataturk desencadear uma ofensiva contra as forças gregas estacionadas na Costa oeste do que viria a ser a Turquia. No seu discurso de vitória, Mustafa Kemal mencionava a aliança entre o "nacionalismo turco e o comunismo soviético" como estando na base da implantação da República da Turquia.

Durante a Primeira Guerra Mundial, a Rússia ocupou o leste de um Império otomano em decadência. Contudo, com a revolução soviética, o fim da Primeira Guerra Mundial e o início da rebelião liderada por Mustafa Kemal com o objetivo de expulsar as potências ocupantes da Turquia, Moscovo mudou consideravelmente a sua posição relativamente à Turquia. A Guerra de Libertação da Turquia era vista como um ato contra o imperialismo ocidental e, como tal, devia ser apoiada por Moscovo (Akçali e Perinçek, 2009, p. 553). A URSS seria a primeira grande potência a reconhecer a República da Turquia ainda durante a Guerra de Libertação (MFA, 2008). Em 1925, a Turquia e a União Soviética chegaram inclusive a assinar um pacto de não-agressão, num contexto de relacionamento positivo entre os dois países que duraria até à Segunda Guerra Mundial (Yinanç, 2010a). Seria a Segunda Guerra Mundial, em que a Turquia manteve, à semelhança de Portugal, uma neutralidade ativa, a marcar o início da deterioração das relações entre os dois países.

A Turquia, à procura do seu lugar no sistema internacional, passou a ter nos Estados Unidos (EUA) um aliado fundamental. Enquanto isso, a URSS estendia a sua zona de influência para a Europa central e de leste, o Cáucaso e a Ásia Central. A neutralidade turca durante o conflito transformar-se-ia numa clara orientação pró-ocidental, principalmente em relação aos EUA, vindo daí a resultar a adesão da Turquia à Organização do Tratado do Atlântico Norte (OTAN) em 1952 e o desenvolvimento de 
um discurso anti-soviético ${ }^{67}$, apropriado às suas novas responsabilidades no contexto bipolar internacional (Warhola e Mitchell, 2006, p. 129). A Turquia passou assim a ser o ponta-de-lança da OTAN no espaço soviético, com metade dos países com quem fazia fronteira a pertencerem ao espaço ou zona de influência soviética: Bulgária, Arménia, Geórgia e Azerbaijão.

A década de 1960 conheceu uma aproximação entre os dois países, ditada pela maior abertura do líder soviético, Nikita Kruschev, assim como pela visível insatisfação da Turquia com o comportamento do seu aliado norte-americano relativamente à questão cipriota (cf. Barrinha, 2010). Exemplo disso foi o acordo estabelecido pelos dois países em 1966 para a construção de uma fábrica de alumínio em Seydişehir, na Turquia, com tecnologia soviética (Ediger e Bagdadi, 2010, p. 229).

Seria contudo necessário esperar até à década de 1980 para que esse relacionamento voltasse a ser reatado, com a abertura política encetada pelo governo turco de Turgut Ozal. Em setembro de 1984, a Rússia e a Turquia assinariam um acordo na área do gás natural. Este acordo é ainda hoje visto como sendo um marco na viragem do relacionamento entre os dois países (Yinanç, 2010a). Ano e meio mais tarde, seria a vez de a empresa russa Gazexport e a empresa turca Botaş assinarem um acordo comercial para um período de 25 anos (Ediger e Bagdadi, 2010, p. 229).

O fim da Guerra Fria libertaria oficialmente a Rússia e a Turquia dos espartilhos geopolíticos que tinham condicionado o relacionamento entre ambos. No início de 1992, o então ministro dos negócios estrangeiros turco, Hikmet Çetin visitou Moscovo, depois de a Turquia ter reconhecido a Federação Russa pouco tempo antes. A visita seria retribuída pelo homólogo russo, Andrei Kozyrev. Em maio do mesmo ano, o primeiro ministro turco Süleyman Demirel assinaria em Moscovo o Tratado sobre os Princípios da Relação entre a República da Turquia e a Federação Russa (MFA, 2008), que serviria de base legal para o relacionamento entre os dois países. As relações durante o período Ieltsin seriam marcadas pela cooperação bilateral.

67 Durante este período, o relacionamento turco-russo piorou significativamente, atingindo pontos caricatos como o facto de os turcos passarem a chamar à salada russa, "salada americana" (Yinanç, 2010a). 
A verdade é que Moscovo continuava a percecionar a Turquia como sendo um representante dos interesses norte-americanos na região. A divergência de interesses entre os dois países relativamente a toda uma série de assuntos certamente não ajudou na mudança dessa perceção (Hill e Taspinar, 2006, p. 83). Com o fim da Guerra Fria, o Cáucaso do Sul e a Ásia Central, passaram, pelos seus laços históricos e culturais, a ser prioridades da política externa turca. Como será analisado mais adiante, a Turquia e a Rússia tinham igualmente posições diametralmente opostas relativamente aos conflitos na Bósnia, no Kosovo e na Chechénia. Por fim, o alargamento da OTAN a leste também não foi benéfico para o relacionamento entre os dois países (idem).

Contudo, rapidamente ficou claro que a Turquia não tinha a capacidade de se afirmar como um ator em todos estes cenários em simultâneo (Weitz, 2010, p. 78), o que de certa forma acalmou Moscovo e, eventualmente, contribuiu para uma aproximação (entre os dois países). Para além do mais, a crise dos mercados asiáticos no final dos anos noventa, que levou a economia russa à beira do colapso, também fez com que esta tivesse de acalmar o seu tom, por vezes agressivo, relativamente à Turquia. Se a isto juntarmos a instabilidade política na Turquia e a crise financeira de 2001, que obrigou este país a solicitar ajuda ao Fundo Monetário Internacional (FMI), temos um contexto bilateral marcado, nos anos noventa, pelo enfraquecimento dos dois países e pelo progressivo alinhamento de prioridades em matéria de política externa (idem, p. 62).

A subida ao poder do Partido da Justiça e do Desenvolvimento (AKP) na Turquia em novembro de 2002, juntamente com a ascensão e consolidação do regime de Vladimir Putin na Rússia permitiu uma rápida alteração neste panorama de fragilidade e levou à aproximação entre os dois países.

A visita de Abdullah Gül a Moscovo em fevereiro de 2004, seria a primeira visita de um ministro dos negócios estrangeiros turco à Rússia desde 1996. Essa visita seria a primeira de várias, sendo de destacar as diversas viagens de Putin 68 à Turquia e do primeiro ministro turco, Recep

68 A visita do presidente russo Vladimir Putin em janeiro de 2005, seria a primeira visita do mais alto dignatário russo à Turquia desde 1972 (MFA, 2008). 
Tayyip Erdogan à Rússia, incluindo uma visita em julho de 2005 ao retiro de verão do presidente russo, em Sochi, na costa do Mar Negro (Hill e Taspinar, 2006, p. 84). Foi numa destas visitas, a primeira de Erdogan a Moscovo, que ambos os líderes assinaram a Declaração Conjunta sobre a Intensificação da Amizade e Parceria Multidimensional entre os dois países (MFA, 2008).

Desde então, os encontros entre altos dignitários dos dois países têm-se multiplicado. Em 2009, por exemplo, teve lugar a visita do presidente Abdullah Gül e do primeiro ministro Recep Tayyip Erdogan a Moscovo e a visita de Vladimir Putin a Ancara. Nessa última, os dois países assinaram mais de vinte protocolos e acordos num claro sinal de aprofundamento e alargamento das áreas de cooperação mútua, como no turismo ou telecomunicações. Em 2010, foi ainda criado um conselho de cooperação estratégica que reúne anualmente o presidente da Rússia com o primeiro ministro turco. O objetivo deste conselho é, sobretudo, a promoção de relações económicas e comerciais entre os dois países. Nesse contexto, foi em 2011 acordada a eliminação da necessidade de vistos de entrada nos respetivos países para visitas inferiores a 30 dias.

Se pelo lado russo, este relacionamento faz parte de uma estratégia de simultânea expansão de laços económicos (e consequente afirmação enquanto potência internacional) e de contenção da influência do mundo ocidental na sua vizinhança, por parte da Turquia, esta aproximação é resultado de uma nova forma de fazer política externa promovida pelo AKP, em particular pelo ministro dos negócios estrangeiros e antigo conselheiro do primeiro ministro para os assuntos internacionais, Ahmet Davutoglu. Na opinião de Bulent Aras, "Davutoglu desenvolveu a sua política externa na base de uma nova imaginação geográfica que põe fim ao que ele apelida de 'alienação' dos países vizinhos da Turquia” (2009, p. 128), incluindo a Rússia. Com base na sua obra Profundidade Estratégia (Stratejik Derinlik) de 2001, Davutoglu definiu uma série de princípios que uma política externa turca ativa deveria ter em consideração. Na sua opinião, a Turquia devia ser capaz de tirar um maior proveito do seu contexto geográfico, dos laços culturais derivados do seu passado histórico e articular tudo isso com uma projeção económica que permitisse exponenciar um crescimento interno que levasse a Turquia a 
assumir um papel central na região e no próprio sistema internacional. Concretamente, isso obrigava a uma política de "zero problemas" com a vizinhança (Altunişik, 2009, p. 30; Davutoglu, 2010) e a uma presença ativa na mesma, marcada pela cooperação económica e não, como até então, pelas questões de segurança (Tekin, 2011, p. 30). Em termos práticos essa aproximação tem levado Ancara a ter uma posição equidistante nas frequentes confrontações entre a Rússia e o ocidente, procurando gerar consensos ao mesmo tempo que desenvolve um relacionamento com Moscovo à margem desses mesmos problemas (Aras, 2009, p. 137).

\section{O relacionamento entre duas potências em ascensão}

Energia e segurança têm, de certa forma, marcado o relacionamento entre Ancara e Moscovo nas últimas décadas. Apesar da franca melhoria no relacionamento entre ambos, a Turquia e a Rússia têm, no que diz respeito às questões centrais do seu relacionamento, posições nem sempre conciliáveis. Veremos nesta parte do capítulo, como esse relacionamento tem evoluído setorialmente, começando pelas questões energéticas.

\section{Questões energéticas}

É a energia, e tem sido a energia, a questão que mais tem unido a Rússia e a Turquia ao longo das últimas décadas. A dependência turca relativamente ao gás e ao petróleo russos tem crescido à medida que tem crescido a sua economia. Dentro deste contexto energético, há duas questões que marcam o relacionamento turco-russo: por um lado, o relacionamento económico entre os dois países, por outro, a geopolítica da questão.

Entre 1996 e 2007, o consumo energético primário da Turquia cresceu praticamente $50 \%$, numa média de cerca de $4 \%$ ao ano. De acordo com estimativas do governo de Ancara esse crescimento será, até 2020, de 6\% ao ano (Coskun e Carlson, 2010, p. 210). O relacionamento com a Rússia, assume nesse contexto um papel fundamental para a Turquia: $63 \%$ do 
gás consumido pela Turquia e $29 \%$ do seu abastecimento de petróleo são provenientes da Rússia (Ediger e Bagdadi, 2010, p. 233). Esta dependência energética resulta num significativo défice na balança comercial entre os dois países, favorável à Russia. Apesar de um volume total de trocas superior a 35 mil milhões de dólares por ano, valor esse que deverá atingir os três dígitos em 2015 (idem), só cerca de um-terço desse valor é que se destina à Turquia, sendo o restante em sentido contrário. Por exemplo, em 2008, ano em que a Rússia passou a ser o maior parceiro comercial da Turquia (Soler i Lecha, 2012, p. 3), o valor do défice comercial de Ancara relativamente a Moscovo situou-se nos 25 mil milhões de dólares (Yinanç, 2010a).

Se é verdade que para alguns autores este volume de trocas pode ser visto como correspondendo ao desenvolvimento de "uma verdadeira parceria estratégica" entre os dois países (Ediger e Bagdadi, 2010, p. 233), esta é, por enquanto, uma parceria economicamente desequilibrada. Não se pode contudo descurar a importância que a Turquia tem para a Rússia enquanto cliente privilegiada dos seus 'produtos' energéticos. Os russos vêem a Turquia como um parceiro energético de importância semelhante à Alemanha: um na Europa do sul e o outro na Europa do norte (Weitz, 2010, p. 66). Para a companhia russa Gazprom, a Turquia é inclusive vista como o seu mais importante cliente (Sergei Komlev apud Yinanç, 2010b).

Como anteriormente mencionado, a questão energética no relacionamento entre a Turquia e a Rússia não se resume ao crescimento no volume de trocas entre os dois países. Há também uma importante dimensão geoestratégica, ligada ao transporte energético e à ideia turca de se afirmar cada vez mais como uma importante plataforma energética a nível regional. É neste contexto que a política dos gasodutos e oleodutos assume uma importância central no relacionamento energético bilateral.

Em 1997, a Rússia e a Turquia assinaram o acordo de construção de um gasoduto que levaria o gás russo do porto de Novorosisk até ao porto turco de Samsun através do Mar Negro. Estava dado o passo inicial para o projeto Blue Stream, que, para além da Rússia e da Turquia, contaria com a participação ativa da Itália através da sua principal empresa energética, a Eni. 
Em 2002, a Turquia começou igualmente a desenvolver, juntamente com diversos parceiros europeus, o projeto Nabucco. A parte europeia do projeto, que ligaria o gasoduto do Cáucaso do Sul à Áustria, possibilitaria a ligação direta entre o Turquemenistão e a Europa, permitindo a diversificação energética e a redução da dependência dos países europeus relativamente à Rússia. O consórcio responsável pela sua exploração anunciou, em 2011, o adiamento do início das obras para 2013 (HDN, 6/05/2011) e não é claro que estas se venham a realizar, em parte por culpa do projeto alternativo proposto pela Rússia.

Moscovo decidiu promover o projeto South Stream, um projeto que prevê o transporte de gás da Rússia para a Bulgária através do Mar Negro e daí para a Grécia, a Itália e a Áustria. Para a Turquia, os dois projetos são compatíveis e não rivais (The Economist, 2009) e por isso, em troca da possibilidade de fazer passar os gasodutos pela sua zona económica exclusiva no Mar Negro, num acordo obtido com a Rússia em agosto de 2009 (Ulutas, 2010, p. 8), a Turquia conseguiu o apoio russo para a construção de um oleoduto do porto de Samsun no Mar do Norte para o terminal de Ceyhan no Mediterrâneo (The Economist, 2009). Esse acordo seria materializado com a visita de Erdogan a Moscovo em janeiro de 2010 (Weitz, 2010, p. 68). Ceyhan é uma peça fundamental no projeto turco de se tornar uma plataforma energética internacional. De acordo com o seu Ministro para a Energia, Taner Yildiz, a Turquia pretende em 2020 fazer passar 3 a 4\% do abastecimento global de gás e 5 a $6 \%$ do abastecimento global de petróleo pelo terminal energético de Ceyhan (Yildiz, 2010, p. 38).

Apesar do apoio russo ser fundamental, é para a Turquia importante que este apoio não se torne numa insustentável relação de dependência, pelo que o governo de Erdogan pretende limitar a 50\% o consumo de gás proveniente de um só abastecedor, uma medida claramente dirigida à Rússia (Coskun e Carlson, 2010, p. 213). O facto de estar ligado ao Azerbaijão através do gasoduto Baku-Tiblisi-Erzurum (BTE) e do oleoduto Baku-Tiblisi-Ceyhan (BTC) permite aliviar um pouco essa dependência (Tekin e Williams, 2009, p. 342). Permite igualmente elevar o valor geoestratégico da Turquia na sua relação com Moscovo: pois se é verdade que a Turquia está bastante dependente da Rússia em termos energéticos, também o é que 
a Rússia necessita da Turquia como plataforma de transporte energético. Neste contexto, a Rússia e a Turquia assinaram uma parceria estratégica em janeiro de 2010 (Ediger e Bagdadi, 2010, p. 232) que prevê o aprofundamento do relacionamento bilateral e que poderá levar, entre outras medidas, ao Blue Stream II, um projeto de criação de um gasoduto que liga a Rússia a Israel através da Turquia.

Para além do petróleo e do gás, a Turquia e a Rússia têm interesses comuns na área do nuclear. A Rússia, em virtude de negociações resultantes da venda dos seus bens energéticos à Turquia, está a construir o primeiro reator nuclear turco, em Mardin, num investimento de 20 mil milhões de dólares. Este corresponde ao maior investimento russo da atualidade no exterior (Akkan, 2012) e é um importante sinal político da aproximação estratégica entre os dois países.

A Turquia joga assim um jogo de ambivalência estratégica com a Rússia no que à energia diz respeito: por um lado pretende afirmar-se internacional e autonomamente como uma plataforma energética à escala global, por outro, sabe que isso só será possível com o apoio de Moscovo, que por sua vez tem na Turquia um dos seus principais parceiros comerciais e energéticos.

\section{Segurança e conflitos}

Relativamente às questões de segurança, há dois aspetos centrais no atual relacionamento Rússia-Turquia: a questão nuclear iraniana e a conflitualidade regional no Sudeste turco, na Chechénia, no Cáucaso do Sul e, mais recentemente, no Médio Oriente, no contexto da Primavera Árabe. Quanto à primeira questão, a convergência entre os dois países relativamente a este tema aparenta ser significativa. Apesar de partirem de pontos diferentes, no sentido em que a Rússia é uma potência nuclear, ao contrário da Turquia, que nunca desenvolveu passos nesse sentido, ambos convergem na necessidade de evitar a proliferação nuclear na sua vizinhança, em particular no Irão. A abordagem de ambos tem contudo

divergido da abordagem dos países ocidentais, uma vez que a Rússia e a Turquia têm procurado ajudar o Irão a desenvolver tecnologia nuclear 
para fins civis. O primeiro ministro turco, em oposição à posição oficial do seu país, considera 'normal' um país no contexto geopolítico do Irão pretender obter armas nucleares (Koprulu, 2009, p. 194). Erdogan chegou em 2010, juntamente com outra potência em ascensão, o Brasil, a acordo com o Irão no sentido de este abdicar da produção de urânio enriquecido. O acordo, posteriormente rejeitado pelo Conselho de Segurança das Nações Unidas (CSNU), previa a transferência de urânio pouco enriquecido (1200 kg) para a Turquia, que continuaria a ser propriedade do Irão, em troca de um reator de pesquisa.

Para a Turquia, é importante chegar a um entendimento com o Irão, sobretudo para evitar uma nova intervenção norte-americana na região e a consequente desestabilização da sua vizinhança. Para a Rússia, que por regra resiste às tentativas norte-americanas de levar a questão iraniana ao CSNU, trata-se não só de limitar a influência norte-americana no Médio Oriente, como de recuperar alguma da influência por si perdida com o fim da Guerra Fria (Hill e Taspinar, 2006, p. 82).

No que à conflitualidade armada interna e regional diz respeito, a Rússia e a Turquia têm por diversas vezes definido posições antagónicas: internamente, o conflito na Chechénia (Rússia) e no Sudeste turco contra os movimentos rebeldes curdos tem levado Ancara e Moscovo a adotar posições contrárias. Externamente, os conflitos no Cáucaso do Sul, em particular o conflito do Nagorno-Karabakh que envolve a Arménia e o Azerbaijão, o Chipre e as guerras dos Balcãs durante os anos 1990 colocaram a Rússia e a Turquia em lados opostos das barricadas. O mesmo sucedendo atualmente no conflito sírio, como veremos mais à frente.

Em termos de conflitualidade interna, a questão curda tem sido uma questão particularmente sensível no relacionamento entre os dois países. A proximidade ideológica entre o Partido dos Trabalhadores do Curdistão (PKK) e a União Soviética, levou a que Moscovo tivesse em vários momentos apoiado direta ou indiretamente a insurreição do movimento de Abdullah Ocalan em pleno território da OTAN. Três décadas depois, a Rússia recusa-se ainda a reconhecer o PKK como um movimento terrorista, algo que deixa Ancara profundamente descontente (The Economist, 2009). Por seu turno, Moscovo gostaria que Ancara apoiasse de forma mais 
ativa os seus esforços de 'normalização' da situação na Chechénia. A Rússia considera que a Turquia não tem sido assertiva o suficiente relativamente a esta questão. Episódios como o desvio de um ferry no Mar Negro por parte dos separatistas chechenos em 1996 ou o cerco, em abril de 2001, ao Swissotel em Istambul durante 12 horas igualmente por parte de um grupo checheno, têm contribuído para esta perceção por parte de Mosocovo (Gorvett, 2011). Afinidades religiosas têm feito com que as reinvidicações chechenas colham simpatia junto da população turca. Aquando da visita de Vladimir Putin a Ancara, em dezembro de 2004, uma manifestação de vários milhares de pessoas concentrou-se nas ruas da capital turca contra a presença do primeiro ministro russo na Turquia. A questão chechena estava no topo das reinvidicações (Warhola e Mitchell, 2006, p. 136). O popular imam turco Tahir Buyukkorukçu fala frequentemente no "porco russo' quando menciona a questão chechena no seu programa televisivo no canal Kon (The Economist, 2009). No seu encontro de julho de 2005, Putin e Erdogan chegaram a um aparente entendimento relativamente a estes dois conflitos internos, reiterando o seu repúdio pelo terrorismo e pelo secessionismo nos seus respetivos territórios (Hill e Taspinar, 2006, p. 84).

Para além das questões internas, o Cáucaso do Sul tem sido uma região que tem ocasionalmente gerado uma forte tensão entre a Rússia e a Turquia. Desde logo o conflito do Nagorno-Karabakh (Weitz, 2010, p. 75) que coloca, desde o final dos anos 1980 frente a frente a Arménia e o Azerbaijão, países que têm na Rússia e Turquia, respetivamente, os seus principais aliados (Terterov et al, 2010, p. 198). A clara melhoria no relacionamento entre Ancara e Ierevan nos últimos anos tem levantado a possibilidade de se estar próximo de um entendimento entre os dois países, para um possível reatamento das relações diplomáticas. Contudo, o envolvimento russo nesse processo levanta suspeitas (The Economist, 2009) de que o verdadeiro objetivo da Rússia é manter o status quo, pois só assim conseguirá manter a sua influência na região e prevenir a ascensão da influência turca (Weitz, 2010, p. 77) numa região que Moscovo considera central aos seus interesses geopolíticos (Torbakov, 2010, p. 37).

De resto, foi obedecendo a essa lógica que a Rússia invadiu parte do território da Geórgia em agosto de 2008. Durante os cinco dias que 
o conflito durou, a Turquia tentou servir de intermediária ao processo, ao mesmo tempo que se coibiu de criticar a Rússia ou de defender a Geórgia (Koprulu, 2009, p. 194). Seria contudo o presidente francês Nicolas Sarkozy a alcançar um cessar-fogo entre as partes. Perspetivando um relacionamento mais estável no longo prazo, Ancara propôs a criação de uma Plataforma de Estabilidade e Cooperação para o Cáucaso (PECC), um projeto que ainda está por se materializar. ${ }^{69}$

Contudo, e apesar da postura defensiva da Turquia, foi de certa forma inevitável que o seu relacionamento com a Rússia sofresse alguns danos causados pela sobreposição de interesses geo-estratégicos (Koprulu, 2009, p. 6). A Turquia rejeitou, numa primeira fase, a entrada de navios norte-americanos no Mar Negro, uma medida que deixou particularmente irritados os seus parceiros da OTAN. Porém, quando Ancara acabou por deixar passar três navios norte-americanos, seria a vez de o governo russo manifestar o seu descontentamento, alegando que a Turquia estava a actuar em violação da Convenção de Montreux de 1936 que regula a passagem de embarcações para o Mar Negro (Weitz, 2010, p. 81). A juntar a isso, a Rússia ficou particularmente insatisfeita por saber que a Turquia, pouco depois do fim do conflito, estava a preparar o envio de equipamento militar para a Geórgia70 (Terterov et al, 2010, p. 198).

Desde 2011, as atenções dos dois países têm-se centrado no Médio Oriente, com a Primavera Árabe no topo da agenda dos dois países. Em particular, na Síria, onde é profundo o desentendimento entre os dois países sobre a melhor política a seguir para resolver o conflito interno entre as forças do regime de Bashar al-Assad e vários movimentos de oposição. A Turquia tem tentado, desde o início da crise, alcançar uma posição comum com a Rússia, mas isso tem-se revelado impossível, em virtude dos diferentes interesses que Ancara e Moscovo têm na Síria:

69 Um aspeto interessante da proposta turca era o facto de esta não ter incluído nem ter avisado antecipadamente os seus parceiros europeus e norte-americanos (Koprulu, 2009, p. 193), facto que agradou à Rússia que viu na proposta um plano de desenvolvimento de relacionamento com a Turquia baseado num jogo de soma nula com os EUA (Torbakov, 2008, p. 26).

70 Já em 2006, a Turquia tinha oferecido 1.8 milhões de dólares em ajuda militar a Tiblisi, com quem de resto mantém um acordo de cooperação na área da defesa (Torbakov, 2008, p. 9). 
para a Rússia trata-se de garantir que a Síria continua a ser uma zona de influência e que lhe garanta a sua presença militar no Mediterrâneo através da (pequena) base naval que possui em Tartus. Para a Turquia, está em causa a instabilidade na sua vizinhança, com implicações diretas para a sua própria estabilidade interna, não só devido ao elevado número de refugiados que diariamente se desloca para a fronteira turca como pela possível criação de um enclave curdo no norte da Síria, o que faria ressuscitar em Ancara os fantasmas do irredentismo curdo. É pois natural que a questão síria seja um tema importante no topo da agenda de relacionamento bilateral entre a Turquia e a Rússia (Donat, 2012).

Contudo, e apesar das profundas divergências entre os dois países relativamente a esta questão, russos e turcos parecem decididos a não deixar que a questão síria mine o seu bom relacionamento. Numa visita de Erdogan a Moscovo em julho de 2012, o primeiro ministro turco e o presidente russo estiveram lado a lado numa conferência de imprensa o tema dominante foi a cooperação económica, tendo somente feito um breve comentário à situação de guerra civil na Síria (Today's Zaman, 2012). Para a Rússia, mais preocupante que a própria diferença de posições relativamente ao regime de Bashar al-Assad, é o facto da política turca para a Síria assinalar uma clara harmonização de posições com os seus parceiros da Aliança Atlântica, o que depois do ainda por concluir episódio da instalação de um sistema de radar anti-mísseis norte-americano na província de Malatya, no sudeste da Turquia ${ }^{71}$, deixa Moscovo particularmente alarmado sobre o grau de re-ajustamento da política externa turca com o ocidente (Bacik, 2012).

Em suma, no campo securitário, a Rússia e a Turquia jogam, uma vez mais, um jogo de ambivalência estratégica, aproximando-se no sentido de promoverem iniciativas comuns - como a participação da Rússia desde 2006 numa operação de policiamento militar no Mar Negro - que ajudem na afirmação das suas posições na região, particularmente em oposição

71 Em setembro de 2011 a Turquia chegou a acordo com os Estados Unidos para instalar um radar antimísseis no contexto do escudo de defesa antimíssil da OTAN, previsto desde a Cimeira de Lisboa, em novembro de 2010 (cf. Shanker, 2011). 
à influência dos EUA (Hill e Taspinar, 2006, p. 82), ao mesmo tempo que procuram limitar essa mesma influência de forma mútua. $O$ atual jogo geopolítico no Médio Oriente é um bom exemplo disso mesmo.

\section{Aspetos definidores do relacionamento entre Ancara e Moscovo}

O relacionamento entre a Rússia e a Turquia é marcado por um curioso paradoxo cultural no sentido em que é a diferença clara entre estes dois países que os torna tão semelhantes no seu comportamento internacional. Ancara e Moscovo privilegiam um relacionamento mútuo assente em princípios realistas, conscientes das suas mais valias e limitações. Há uma tentativa clara de explorar sinergias onde estas são uma clara mais valia, sem a necessidade de incluir discursos de proximidade ideológica ou cultural. No que concerne ao relacionamento mútuo, a Rússia e a Turquia procuram expandir as suas zonas de influência, ao mesmo tempo que privilegiam a cooperação de curto prazo em matérias de interesse mútuo, num discurso pautado pelo interesse nacional (Aras, 2009, p. 137) e esvaziado de alusões normativas. Como referem James Warhola e William Mitchell (2006, p. 138):

"Para o bem e para o mal, as relações entre a Federação Russa e a República Turca têm sido poupadas a complicações derivadas de um possível questionamento relativamente aos tipos de regime político, a alegações de abusos de direitos humanos ou a posturas político-morais de ambos os lados relativamente ao outro."

Um aspeto interessante no relacionamento entre estes dois países diz respeito à sua 'utilidade' na autonomização (no caso da Turquia) e na afirmação (no caso da Rússia) das suas políticas externas face aos EUA. Como tivemos ocasião de ver no caso dos conflitos no Cáucaso do Sul, apesar de nem sempre haver um entendimento entre Ancara e Moscovo, é claro para ambos que os EUA não devem ter uma posição predominante na região (Koprulu, 2009, p. 194). O mesmo se aplica à Ásia Central 
(cf. Warhola e Mitchell, 2006), em que os interesses russos e turcos são bastante semelhantes: combate ao terrorismo e crime organizado, e exploração de recursos energéticos (Weitz, 2010, p. 79). Em questões centrais da segurança internacional que envolvem os EUA, tanto a Turquia como a Rússia adotam, frequentes vezes, posições semelhantes: é assim relativamente à questão nuclear no Irão, foi assim relativamente ao apoio à invasão do Afeganistão e foi assim relativamente à oposição à invasão do Iraque (The Economist, 2009).

Foi possivelmente no sentido de fortalecer um eventual distanciamento de Ancara relativamente ao ocidente que a Rússia apoiou a entrada da Turquia para a Organização de Cooperação de Xangai com o estatuto de 'parceiro de diálogo' (Today's Zaman, 2011). Contudo, as boas relações entre o presidente norte-americano Barack Obama e o primeiro ministro turco Recep Tayyip Erdogan, juntamente com a aproximação estratégica no quadro da OTAN e no contexto da Primavera Árabe, têm, de certa forma, levado a um relativo 'fracasso' desta estratégia. É visível a importância estratégica atribuída pela atual administração americana às suas relações com a Turquia: no conflito sírio, a Turquia e os EUA surgem, frequentemente, lado a lado e nem o 'verão quente' turco, com milhões de pessoas nas ruas a exigir mudanças na política do governo do AKP, levou a mais do que um simples puxão de orelhas por parte de Washington.

\section{Conclusão}

Como tivemos oportunidade de observar ao longo deste capítulo, a Rússia e a Turquia têm hoje em dia um relacionamento de convergências de interesse, particularmente interesses económicos e energéticos. Este relacionamento pode ser explicado internamente pela existência de lideranças políticas fortes e estáveis - Erdogan na Turquia, Putin na Rússia - e externamente por um contexto internacional favorável à ascensão de um conjunto de potências emergentes no sistema internacional, que, particularmente após a crise financeira de 2008, adquiriram um protagonismo crescente na esfera internacional (Onis, 2011, p. 48). O tipo de 
relação entre a Rússia e a Turquia deve pois ser entendido, não somente como algo de específico a estes dois países, mas como algo que pode ser exemplificativo do padrão de relacionamento que progressivamente marca este mundo pós-americano (Zakaria, 2008): uma relação forte, desprovida de grandes princípios morais e focada sobretudo na prossecução de objetivos de natureza económica. Esta não é uma relação definida por qualquer proximidade cultural, por fortes laços de confiança (Terterov, 2010, p. 198) ou por uma grande substância política (Hill e Taspinar, 2006, p. 90); é, sobretudo, uma relação pragmática. Por isso, independentemente da maior ou menor aproximação da Turquia ao ocidente, da divergência de opiniões relativamente ao conflito sírio, ou da contradição de interesses no Cáucaso, o relacionamento entre Rússia e Turquia continuará a ser pautado pelo interesse estratégico dos dois países.

\section{Bibliografia}

AKKAN, Faruk - Turkey, Russia improve ties, eye further cooperation. Today's Zaman, 1 janeiro 2012. [Acedido a 5 de ago. de 2012]. Disponível na Internet: http://www. todayszaman.com/news-267353-turkey-russia-improve-ties-eye-further-cooperation.html.

ALTUNISIK, M. - Turkey's new activism in the Middle East. Negócios Estrangeiros. N. ${ }^{\circ} 14$ (2009), p. 29-39.

AKÇALI, Emel e PERINÇEK, Mehmet - Kemalist Eurasianism: An Emerging Geopolitical Discourse in Turkey. Geopolitics. Vol. 14 (2009), p. 550-569.

ARAS, Bulent - The Davutoglu Era in Turkish Foreign Policy. Insight Turkey. Vol. 11, N. 3 (2009), p. 127-142.

BACIK, Gokhan - Turkey and Russia in the Arab Spring: Straining Old Rifts Further?. On Turkey Series, The German Marshall Fund of the United States, 2012.

COSKUN, Bezen Balamir e CARLSON, Richard - New Energy Geopolitics: Why does Turkey Matter?. Insight Turkey. Vol. 12, N. ${ }^{\circ} 3$ (2010), p. 205-220.

DAVUTOGLU, Ahmet - Turkey's Zero-Problems Foreign Policy. Foreign Policy. 2010. [Acedido a 26 de ago. de 2012]. Disponível na Internet: http://www.foreignpolicy.com/articles/2010/05/20/ turkeys_zero_problems_foreign_policy?print=yes\&hidecomments=yes\&page=full.

DONAT, Gozde Nur - Turkey tries best to convince Russia, Iran to help solve Syrian crisis. Today's Zaman, 26 agosto 2012. [Acedido a 15 de set. de 2012]. Disponível na Internet: http://www.todayszaman.com/news-290512-turkey-tries-best-to-convince-russia-iran-tohelp-solve-syrian-crisis.html.

Economist, The - Turkey and Russia. Old Rivals, new partners, 13 agosto 2009. [Acedido a 12 de set. de 2012]. Disponível na Internet: www.economist.com/node/14216768.

EDIGER, Volkan e BAGDADI, Itir - Turkey-Russia Energy Relations: Same Old Story, New Actors. Insight Turkey. Vol. 12, N. 3 (2010), p. 221-236. 
GORVETT, Jon - Chechen Question Harms Turkish-Russian Relations. Eurasia Insight. 2002. [Acedido a 5 de jun. de 2011]. Disponível na Internet: http://www.eurasianet.org/ departments/insight/articles/eav110702a.shtml.

HILL, Fiona e TASPINAR, Omer - Turkey and Russia: Axis of the Excluded?. Survival. Vol. 48, N. $^{\circ} 1$ (2006), p. 81-92.

Hurriyet Daily News - Nabucco start delayed as North Stream moves ahead, 6 junho 2011. [Acedido a 12 de set. de 2012]. Disponível na Internet: http://www.hurriyetdailynews.com/ default.aspx?pageid=438\&n=nabucco-start-delayed-as-north-stream-moves-ahead-2011-05-06.

KAZAN, Isil - Turkey: Where Geopolitics still matters. Contemporary Security Policy. Vol. 26, N. $^{\circ} 3$ (2005), p. 588-604.

KOPRULU, Kemal - Paradigm Shift in Turkey's Foreign Policy. Brown Journal of World Affairs. Vol. XVI, N. ${ }^{\circ} 1$ (2009), p. 185-201.

Ministry of Foreign Affairs - Turkey's Political Relations with Russian Federation, 2008. [Acedido a 6 de jun. de 2011]. Disponível na Internet: http://www.mfa.gov.tr/turkey_spolitical-relations-with-russian-federation.en.mfa.

ONIS, Ziya - Multiple Faces of the 'New' Turkish Foreign Policy: Underlying Dynamics and a Critique. Insight Turkey. Vol. 13, N. ${ }^{\circ} 1$ (2011), p. 47-65.

ROBERTS, John - Turkey as a Regional Energy Hub. Insight Turkey. Vol. 12, N. 3 (2010), p. 39-48.

SHANKER, Thom - U.S. Hails Deal with Turkey on Missile Shield. The New York Times, 15 setembro 2011. [Acedido a 26 de out. de 2012]. Disponível na Internet: http://www. nytimes.com/2011/09/16/world/europe/turkey-accepts-missile-radar-for-nato-defenseagainst-iran.html?_r=0.

SOLER I LECHA, Eduard - The Conceptual Architecture of Turkish Foreign Policy: An update in light of regional turbulence. Documentos CIDOB. N. ${ }^{\circ}$ 18, 2012.

TEKIN, Ali e WILLIAMS, Paul - EU-Russian Relations and Turkey's Role as an Energy Corridor. Europe-Asia Studies. Vol. 61, N. ${ }^{\circ} 2$ (2009), p. 337-356.

TEKIN, Caner - Turkish foreign policy in the 21st century: institutional idealism revisited. Turkish Review. Vol. 1, N. ${ }^{\circ} 4$ (2011), p. 30-35.

TERTEROV, Marat; VAN POOL, John e NAGORNYY, Sergiy - Russian Geopolitical Power in the Black and Caspian Seas Region: Implications for Turkey and the World. Insight Turkey. Vol. 12, N. ${ }^{\circ} 3$ (2010), p. 191-203.

Today's Zaman - Turkey disappointed over third veto of UN draft resolution on Syria, 20 julho 2012. [Acedido a 12 de ago. de 2012]. Disponível na Internet: http://www. todayszaman.com/news-287104-turkey-disappointed-over-third-veto-of-un-draft-resolutionon-syria.html.

Today's Zaman - Turkey to become 'dialogue partner' at SCO, 4 novembro 2011. [Acedido a 14 de ago. de 2012]. Disponível na Internet: http://www.todayszaman.com/news261928-turkey-to-become-dialogue-partner-at-sco.html.

TORBAKOV, Igor - The Georgia Crisis and Russia-Turkey Relations. Washington DC: The Jamestown Foundation, 2008.

TORBAKOV, Igor - Russia and Turkish-Armenian Normalization: Competing Interests in the South Caucasus. Insight Turkey. Vol. 12, N. ${ }^{\circ} 2$ (2010), p. 31-39.

ULUTAS, Ufuk - Turkish Foreign Policy in 2009: a Year of Pro-activity. Insight Turkey. Vol. 12 , N. ${ }^{\circ} 1$ (2010), p. 1-12.

WARHOLA, James e MITCHELL, William - The Warming of Turkish-Russian Relations: Motives and Implications. Demokratizatsiya. Vol. 14, N. ${ }^{\circ} 1$ (2006), p. 127-143. 
WEITZ, Richard - Russian-Turkish Relations: Steadfast and Changing. Mediterranean Quarterly. Vol. 21, N. ${ }^{\circ} 3$ (2010), p. 62-85.

YILDIZ, Taner - Turkey's Energy Policy, Regional Role and Future Energy Vision. Insight Turkey. Vol. 12, N. ${ }^{\circ} 3$ (2010), p. 33-38.

YINANÇ, Barçin - Old rivals, new partners: Turkey and Russia's journey from Cold War to hot sun, Hurriyet Daily News, 8 agosto 2010a. [Acedido a 12 de ago. de 2012]. Disponível na Internet: http://www.hurriyetdailynews.com/default. aspx? pageid=438\&n=from-coldwar-to-hot-sun-2010-08-06.

YINANÇ, Barçin - Old rivals, new partners: Russia and Turkey, tied by energy dependence, Hurriyet Daily News, 8 setembro 2010b. [Acedido a 12 de ago. de 2012]. Disponível na Internet: http://www.hurriyetdailynews.com/default.aspx?pageid=438 $\&$ n=russia-andturkey-tied-by-energy-dependence-2010-08-09.

ZAKARIA, Fareed - The Post-American World. New York: W. W Norton \& Company Ltd, 2008. 
